\title{
Crecimiento urbano, ilegalidad y poderes locales en la ciudad de Puebla*
}

\section{Patrice Mele**}

En este trabajo se intenta delimitar teóricamente y en la situación de la ciudad de Puebla, el espacio de la ilegalidad. El autor se propone mostrar que la separación entre crecimiento urbano legal e ilegal, no es adecuado para la urbanización mexicana. Después de revisar conceptos y desarrollos teóricos de diferentes investigadores que han tratado el fenómeno de la marginalidad y la ilegalidad, se considera la situación concreta de la ciudad de Puebla, tomando en cuenta cómo las autoridades han definido la urbanización ilegal y cómo se han venido presentando las formas de producción del espacio urbano. El autor concluye que es mejor definir la dinámica de la urbanización como expresión de diferentes actores y no oponiendo un mercado legal a otro ilegal afirmando, asimismo, que la ilegalidad debe estudiarse a partir de las condiciones sociales en las que surge.

\section{Introducción}

El estudio del problema de la ilegalidad en la vida urbana y, más particularmente, de la ilegalidad en el crecimiento urbano de Puebla, la cuarta ciudad de México, obliga a tratar de delimitar, tanto teóricamente como en la situación local, el espacio de la ilegalidad. ${ }^{1}$

La ilegalidad puede ser definida como lo que es contrario a la ley y, por extensión, lo que está fuera de la ley, lo que la ley no puede controlar. El espacio de la ilegalidad sería, entonces, lo negativo del espacio de la legalidad. La ilegalidad es el irrespeto, la desviación de la norma, del acto legislativo fundador del poder del Estado.

Plantear el problema de la ilegalidad es, por ende, reconocer la importancia que para la geografía urbana tiene el llevar a cabo un análisis político de la ciudad, del poder en la ciudad.

No obstante, es necesario hacer notar que la legalidad, y por

* Traducción del francés de Mario Zamudio.

** Investigador del CREDal (Francia) y de la División de Estudios Urbanos del Instituto de Ciencias de la Universidad Autónoma de Puebla

${ }^{1}$ Este texto es una versión modificada y actualizada de la ponencia presentada en el grupo de trabajo "Corruption, Informality and Illegality in Urban Life". Institute of British Geographers, Portsmouth, 8 de enero de 1987. 
lo tanto la ilegalidad, no debe considerarse como un estado, sino como una relación social, una relación con la norma, que es la que establece la separación, y una relación con el poder administrativo y político, que•es el que define la norma, la ley y su aplicación, sus interpretaciones legítimas y las que no lo son.

En este trabajo nos proponemos mostrar que la separación que establecen tanto las ciencias sociales como los discursos de las instancias de administración de la ciudad, entre un crecimiento urbano "legal" y un crecimiento urbano "ilegal", no es adecuado para el análisis de la urbanización mexicana. Mediante el estudio de las contradicciones entre la norma y la realidad del crecimiento urbano de la ciudad de Puebla, veremos aparecer la función que desempeña la "ilegalidad" en cuanto designación en la manera como las instancias del poder local y federal mexicano llevan a cabo la administración social de la ciudad.

\section{Una dualidad fundamental entre el crecimiento legal y el crecimiento ilegal}

\section{A) La ilegalidad y el análisis de la ciudad}

El concepto de "marginalidad", bajo formas diferentes y a pesar de numerosas polémicas, tiene como referente espacial implícito la división entre dos tipos de espacios urbanos y de poblaciones urbanas. Ya sea que el análisis de esa división tenga una connotación marxista - cuando insiste en la creación de un ejército industrial de reserva y de una sobrepoblación relativa resultado del desarrollo capitalista- ${ }^{2}$ o una connotación liberal - cuando la división es percibida como una "integración todavía no realizada" de una parte de la población [Bennholdt 1981:1506-1507; Oliven 1981:1627-1628), la constitución de un universo marginal segregado social y físicamente es reconocida, de manera más o menos explícita, como un rasgo fundamental de la urbanización latinoamericana.

Ahora bien, ese universo marginal es asociado con cierta forma de crecimiento urbano - la ciudad perdida creada por inva-

\footnotetext{
${ }^{2}$ Quijano (1966) distingue entre el punto de vista del "estructuralismo funcionalista", para el que la falta de integración de un elemento de la estructura tiene como causa las características de ese elemento, y el "estructuralismo histórico", para el que la marginalidad de un elemento tiene como causa las contradicciones de la propia naturaleza y de las tendencias de la estructura social; citado por Oliven $[1981: 1623)$.
} 
sión o la colonia popular "ilegal"-, ya sea por un análisis ecológico que asimila una forma espacial a una categoría social, ya por un análisis de] rechazo que invoca la necesidad que tiene cierta categoría social de encontrar vivienda lejos de la ciudad, sin servicios urbanos y sin beneficiarse de la protección de la ley.

Más a menudo, como lo hace notar Zúñiga [1985:470], el concepto de marginalidad es definido como una falta, una carencia: de participación social, de integración a los sectores económicos dominantes, de condiciones de vivienda.

Las críticas de la sociología urbana marxista (Castells, 1985:154-157; Pradilla, 1984) insisten en el carácter ideológico de la asimilación entre estructura social y estructura espacial y en la inclusión de personas integradas al sistema económico dominante (obreros, comerciantes en pequeño) en los espacios de la marginalidad; no obstante, si bien se pone en tela de juicio la adecuación entre marginalidad urbana y marginalidad social, no se pone en duda la noción de marginalidad como concepto funcional para distinguir un tipo de espacio que es el resultado de la necesidad absoluta de vivienda de una población sin otro recurso. La marginalidad urbana continúa siendo designada implícitamente como el conjunto de los procesos ilegales (fuera de las normas y del mercado) de producción del espacio urbano. Aunque los autores que utilizan el término de marginalidad lo emplean como un concepto explicativo o descriptivo de las nuevas divisiones sociales que surgen en los países subdesarrollados, infieren siempre una traducción espacial. A la exclusión del mercado del empleo, que constituye la marginalidad económica, corresponde, sin sobreponerse plenamente, una marginalidad "ecológica", "urbana”, que sería la exclusión del mercado, público o privado, de la vivienda; y esa marginalidad "ecológica", habida cuenta de las condiciones específicas del crecimiento urbano de las metrópolis de los páíses subdesarrollados, sería mucho mayor que la marginalidad "económica” (Quijano, 1971:72-77).

La imagen que más a menudo se relaciona con los marginados urbanos es la invasión de tierra como necesidad inmediata de vivienda y "única salida dejada a las masas populares" (Núñez 1984:101) para adquirirla, si bien Núñez hacè notar que la situación mexicana es diferente, ya que las compras clandestinas son más importantes que las invasiones debido a la fuerte represión de las primeras invasiones en los años 1950.

Por lo tanto, traducido a términos espaciales, el universo social de la marginalidad es, esencialmente, el universo de la ilegalidad.

Aparte de la influencia que ejercen sobre él las teorías de la marginalidad urbana, el análisis de la urbanización latinoameri- 
cana se ve fuertemente influido también por las tesis de Turner, quien delimita lo que él llama "asentamientos humanos no regulados" (Turner 1975:475-476), término que abarca los "villorrios de chozas", los asentamientos de hecho y las subdivisiones clandestinas. Una vez más, una de las bases del análisis es la delimitación de lo "legal" y lo "ilegal", de lo planificado y lo no planificado, utilizada para distinguir dos tipos de espacios urbanos. Por lo demás, Turner insiste en el carácter institucional del problema y en la necesidad de la supresión de la ilegalidad de la tenencia individual como primer paso que permite la consolidación y el mejoramiento de las condiciones de la vivienda y de las zonas urbanas "ho reguladas". La ilegalidad es atributo de la marginalidad, síntoma y síndrome de exclusión, por lo que Turner propone hacer de ella, por sobre los problemas de dotación de servicios y de inversión pública, el elemento clave de la integración de la ciudad, de la consolidación de los "asentamientos humanos no regulados". La legalidad bajo la forma de títulos de propiedad es presentada como la aportación de una seguridad mínima acordada a los residentes que les permite pasar del estado de un comportamiento de necesidad al de pequeños propietarios urbanos.

Los geógrafos que se ocupan de los problemas urbanos de las ciudades de los países subdesarrollados pasan de la descripción de las formas de hábitat al análisis de una urbanización espontánea, subintegrada. En 1967, Pierre George definía así el uso del término "hábitat espontáneo": ". . designa una ocupación de hecho de una fracción del suelo urbano por categorías de población para las que el acceso a las formas legales de vivienda es imposible. .." (George 1967:13). Yves Lacoste [1976:157) propone tres criterios que reencontramos en la mayoría de los análisis del hábitat de las ciudades de los países subdesarrollados: la precariedad, la ilegalidad de la tenencia de la tierra y el temor constante al desalojo; la precariedad de la construcción hecha "de cualquier modo" y la carencia de los equipamientos urbanos básicos. Al mismo tiempo que insiste en la necesidad de tomar en cuenta muchos otros factores, Alain Durand Lasserve (Durand Lasserve 1986:34) propone, como línea de demarcación para una primera identificación de las prácticas inmobiliarias, el "plano del derecho": la división entre lo legal y lo ilegal, entre lo que se hace y lo que debería hacerse.

Naciri, en un intento de síntesis y precisión del concepto de "subintegración", propone una medida de esta última mediante la multiplicación de los criterios que la separan de lo que él llama la "ciudad de referencia", espacio de la legalidad, de los servicios modernos, de los modelos de urbanización dominantes de las so- 
ciedades industrializadas. Él distingue dos tipos de desarrollo urbano, "el que implica la introducción de equipamiento previo en los terrenos sobre los que habrá de construirse y el modo de crecimiento indiferente a ese equipamiento indispensable del suelo urbano" (Naciri, 1980:38). Sin embargo, no se trata sólo de medir los servicios urbanos para determinar el nivel de integración a la ciudad, porque, para él, la "subintegración de una forma de hábitat no es solamente una diferencia de gradn, es también una diferencia de naturaleza". Y esa diferencia de naturaleza debe buscarse en la génesis de los espacios urbanos, en su planificación ante-. rior, en la legalidad y en la legitimidad de su implantación.

\section{B) La ilegalidad como designación}

En el escenario público de la ciudad de Puebla, se define precisamente lo que sería una urbanización de derecho, crecimiento legitimo de la ciudad, frente a una urbanización de hecho, subintegrada, crecimiento ilegítimo, "enfermedad de la ciudad". En cada mención de los barrios pobres, los periódicos locales retoman una designación de esos espacios en términos de exclusión de la ciudad. Las autoridades municipales de la ciudad asimilan el conjunto del espacio urbano periférico a un espacio de la subintegración.

En ocasión de una de sus visitas a los fraccionamientos ilegales de la periferia de la ciudad, el anterior presidente municipal declaró: "el subdesarrollo de los barrios pobres detiene el progreso equilibrado de la ciudad de Puebla y provoca una carga onerosa a los municipios poblanos." " Consecuentemente, el desarrollo de la ciudad se ve frenado por los barrios "subintegrados", que en lo sucesivoison considerados como responsables de los problemas de la ciudad.

Otras declaraciones hacen alusión a un perímetro urbano oficial, constituido por el conjunto de fraccionamientos y barrios integrados al espacio público, ${ }^{4}$ al que, según esas declaraciones, se limita la intervención legítima de los poderes públicos. En el curso de otra visita de trabajo a los fraccionamientos "ilegales" y las zonas ejidales urbanizadas del sur de la ciudad, el anterior presidente municipal anunció a la población reunida en asamblea que, puesto que se trataba de asentamientos "ilegales", el municipio no estaba obligado a responder a las demandas de los habitan-

${ }^{3}$ Jorge Murad, El Sol de Puebla, 16 de abril de 1984.

4 Es decir, aquellos que el municipio ha tomado oficialmente a su cargo. 
tes y ni siquiera a considerarlas, pero que, ante la importancia de los problemas y aunque esos espacios no los hubiera tomado oficialmente a su cargo el municipio, en su calidad de presidente del mismo intentaría ayudar a esos pobladores a mejorar sus condiciones de vida. Como vemos, esos habitantes no poseen ningún "derecho de ciudadanía" que puedan hacer valer, ningún derecho a los servicios municipales, pero el presidente municipal se compromete a ayudarlos, no como un deber de su administración, sino bajo la modalidad de un juramento de fidelidad necesario hecho a su persona, representante del poder del PRI (Partido Revolucionario Institucional).

En el curso de su campaña, el candidato del PRI y futuro presidente municipal declaró que una de sus principales preocupaciones eran las condiciones en que vivían los habitantes de los "barrios marginados, que son asentamientos ilegales y, por ese hecho, no cuentan con los servicios indispensables y se debaten en la pobreza y la insalubridad". 5 En boca de un futuro administrador de la ciudad, la ilegalidad es presentada como causa de la falta de equipamiento urbano y de la pobreza.

De esos análisis y discursos sobre la ciudad se desprende una concepción de la ilegalidad como criterio fundamental de división entre dos tipos de crecimiento urbano: uno, regido por la ley, las normas urbanísticas y las reglas del mercado de los terrenos para construcción; el otro, fuera de la norma, próximo a la clandestinidad. Entre el universo de la legalidad y el de la ilegalidad, no hay lugar para situaciones intermedias, la separación es clara, todo lo que no es legal es ilegal, la ilegalidad es una falta de legalidad que debe suprimirse.

\section{Las formas de producción del espacio urbano en la ciudad de Puebla}

Fuera de las recientes intervenciones de los organismos públicos de vivienda, la imagen del crecimiento urbano de la ciudad de Puebla es la casa individual. Si bien la omnipresencia de esta imagen podría validar un análisis del crecimiento urbano como la suma de proyectos individuales, los conjuntos que aparecen enseguida y la génesis de esos espacios periféricos hacen necesario un estudio de la producción del espacio urbano desde el punto de vista de las ramificaciones de la promoción de bienes ráces e inmobiliarias (véase Durand Lasserve y Tribillon, 1983:9-37).

\footnotetext{
${ }^{5}$ Guillermo Pacheco Pulido, El Sol de Puebla, 17 de noviembre de 1986.
} 
Entre las formas principales del crecimiento urbano de la ciudad de Puebla, es posible distinguir cuatro tipos de fraccionamientos:

- los fraccionamientos o conjuntos "privados", aprobados conforme a las normas oficiales;

- los fraccionamientos o conjuntos "ilegales", creados sin autorización oficial; dales, y

los fraccionamientos "ilegales" establecidos en tierras eji-

- los fraccionamientos o conjuntos habitacionales "públicos".

La tipología propuesta retoma la división entre "legal" e "ilegal" y define inmediatamente dos de las formas de crecimiento por su ilegalidad. Esas dos formas ilegales ocupan la mayor parte del espacio urbano de nueva creación (Mele, 1985). Aunque retomamos la división que buscamos poner en tela de juicio, intentaremos precisar, en el caso de cada tipo de promoción, su relación con la legalidad y con las instanciàs administrativas. Además, veremos que la división entre lo ilegal y lo legal no es muy clara y que no se limita necesariamente a lo público, ya que existen múltiples instancias de legitimación del crecimiento urbano.

Lo que intentamos hacer en primer lugar es definir lo que podría ser un espacio de la legalidad; es decir, enfocar la ilegalidad desde su contrario, la ley, la norma y el plan de equipamiento. Pero veremos que el espacio de la legalidad se nos escapa o, más bien, se limita a algunos fraccionamientos privados aprobados, lo que nos obligará a intentar redefinir la noción de "ilegalidad".

\section{A) El espacio de la legalidad}

Una forma codificada del crecimiento urbano: el fraccionamiento privado

El desarrollo de un fraccionamiento está regido por la Ley de Fraccionamientos del Estado de Puebla, publicada el 20 de diciembre de $1974 .^{6}$ Se trata de la única forma reglamentada del crecimiento urbano. En el texto no se establece diferencia alguna entre los conjuntos habitacionales públicos, los privados o los grupos de inmuebles en condominio, que dependen de la misma re-

6 "Ley de Fraccionamientos del Estado de Puebla", en Periódico Oficial del Gobierno Constitucional del Estado Libre y Soberano de Puebla. Puebla, 20 de diciembre de 1974. 
glamentación, como tampoco, por lo demás, entre las zonas industriales, consideradas como fraccionamientos industriales, y los fraccionamientos de residencias secundarias o turísticas. El término "fraccionamiento" puede designar cualquiera de esas formas, con excepción, no obstante, de los inmuebles colectivos. En ese contexto, más que división y venta de lotes, la definición del fraccionamiento podría ser: la concesión, hecha por los poderes públicos a una persona privada del derecho de llevar a cabo una venta parcelaria de tierras o de viviendas con la obligación de hacerse cargo de la introducción de los servicios; ${ }^{7}$ por ende, se trata de un modelo de crecimiento urbano mediante la integración de un espacio urbano construido, en el sentido urbánístico de instalación de los servicios urbanos.

Entre 1970 y 1987, 1536 hectáreas fueron incorporadas al espacio urbano en la forma de fraccionamientos privados y se pusieron a la venta 46465 lotes en 92 fraccionamientos. ${ }^{8}$

No obstante, es necesario ver que esos totales ocultan realidades diferentes y que, si bien el número de lotes corresponde a la división inicial, a menudo esos lotes son reagrupados o bien no son vendidos inmediatamente. La aprobación de un fraccionamiento no debe ser considerada como representativa del espacio fraccionado, pero ese criterio puede ser utilizado para identificar el paso de un espacio al mercado del terreno para construcción.

La ciudad se extiende, al mismo tiempo que conserva dentro del perímetro urbanizado numerosos espacios vacíos, y cada nuevo fraccionamiento refuerza esa tendencia. En 1980, el plan director urbano de Puebla hacía notar la existencia de un $20 \%$ de lotes baldíos dentro del perímetro urbano.

${ }^{7}$ Los fraccionamientos urbanos se dividen actualmente en tres categorías: de "primera", "medio" y "popular", y sus lotes tienen una superficie mínima de 300,160 y $120 \mathrm{~m}^{2}$, respectivamente. La construcción no debe exceder $80 \%$ del lote en ninguno de los tres casos. La ley obliga al fraccionador a introducir todos los servicios urbanos, a proveer el suministro de agua y a tealizar las redes de vialidad y de alumbrado público. Las redes telefónicas no son obligatorias para los fraccionamientos populares; ésta es la única diferencia entre las tres categorías en el plano de los servicios. El fraccionador debe obtener la autorización de la Secretaría de Asentamientos Humanos y Obras Públicas del Estado de Puebla [SAHOPEP] y la del municipio antes de comenzar los trabajos, y sólo puede vender los lotes después de haber terminado las obras de urbanización, que es cuando el municipio toma a su cargo el fraccionamiento.

${ }^{8}$ Las fuentes que consultamos fueron los expedientes de fraccionamientos que se encuentran en los archivos del municipio y de la SAHOPEP y que remontan hasta 1940, pero se puede considerar que esos archivos son exhaustivos únicamente a partir de 1970. Nuestras fuentes fueron verificadas y actualizadas gracias a la lista que está elaborando la Arq. María Luisa Contreras como parte del Programa de Estudios Municipales de la Universidad Autónoma de Puebla. 
Por lo tanto, el fraccionamiento no puede ser considerado exclusivamente como un tipo de venta de terrenos "para construcción"; también debe ser considerado como un proceso que permite una forma de especulación específica; un procedimiento que, mediante una división, permite a los pequeños capitales el acceso a la especulación con bienes raíces. Podemos suponer que la realización de un gran número de fraccionamientos sería imposible sin esa segunda etapa de la promoción que permite al fraccionador recuperar su inversión rápidamente, puesto que es relevado en el proceso de venta por otros inversionistas/especuladores que poseen una menor capacidad de inversión.

En Puebla es posible señalar dos tipos de especulación con bienes raíces que condicionan las formas del crecimiento urbano:

la especulación con grandes terrenos en la periferia del espacio urbanizado que requiere una fuerte inversión y está reservada a los propietarios de los terrenos, a la gran burguesía y a las sociedades inmobiliarias, $y$

E la especulación "lote por lote" en el espacio urbanizado, accesible a capas de población más modestas, en el que una gran parte de las clases medias encuentra una forma de inversión interesante y negociable en todo momento.

A pesar de que la ley establece estrictamente los términos, la integración jurídica del fraccionamiento, y por ende de su legalidad, es puesta en tela de juicio por la realidad de la urbanización. De los 92 fraccionamientos que han sido autorizados a partir de 1970 , el municipio ha tomado a su cargo solamente 52; por lo tanto, sólo éstos son considerados como parte del perimetro urbano oficial de la ciudad de Puebla por los responsables de la Secretarfa de Asentamientos Humanos y Obras Públicas del Estado de Puebla [SAHOPEP] y por las autoridades municipales. ${ }^{9}$ En su mayoría, los fraccionamientos fueron vendidos antes de la conclusión de los trabajos de urbanización.

Los fraccionadores utilizan el contrato de "promesa de ven. ta", que obliga al comprador a hacer un pago mucho antes de que la venta sea registrada por un notario. "Teóricamente", los notarios no pueden dar su caución a una venta antes de haber recibido la autorización del municipio.

Esos contratos son considerados como ilegales y sin valor jurídico y, oficialmente, constituyen un delito; sin embargo, nunca han sido anulados ni se ha aplicado sanción alguna a los frac-

9 Véase el mapa 1, "La ciudad legal", y el mapa 2, "Espacios de la ilegalidad". 
MAPA 1

Procesos de producción del espacio urbano de la ciudad de Puebla. La ciudad legal

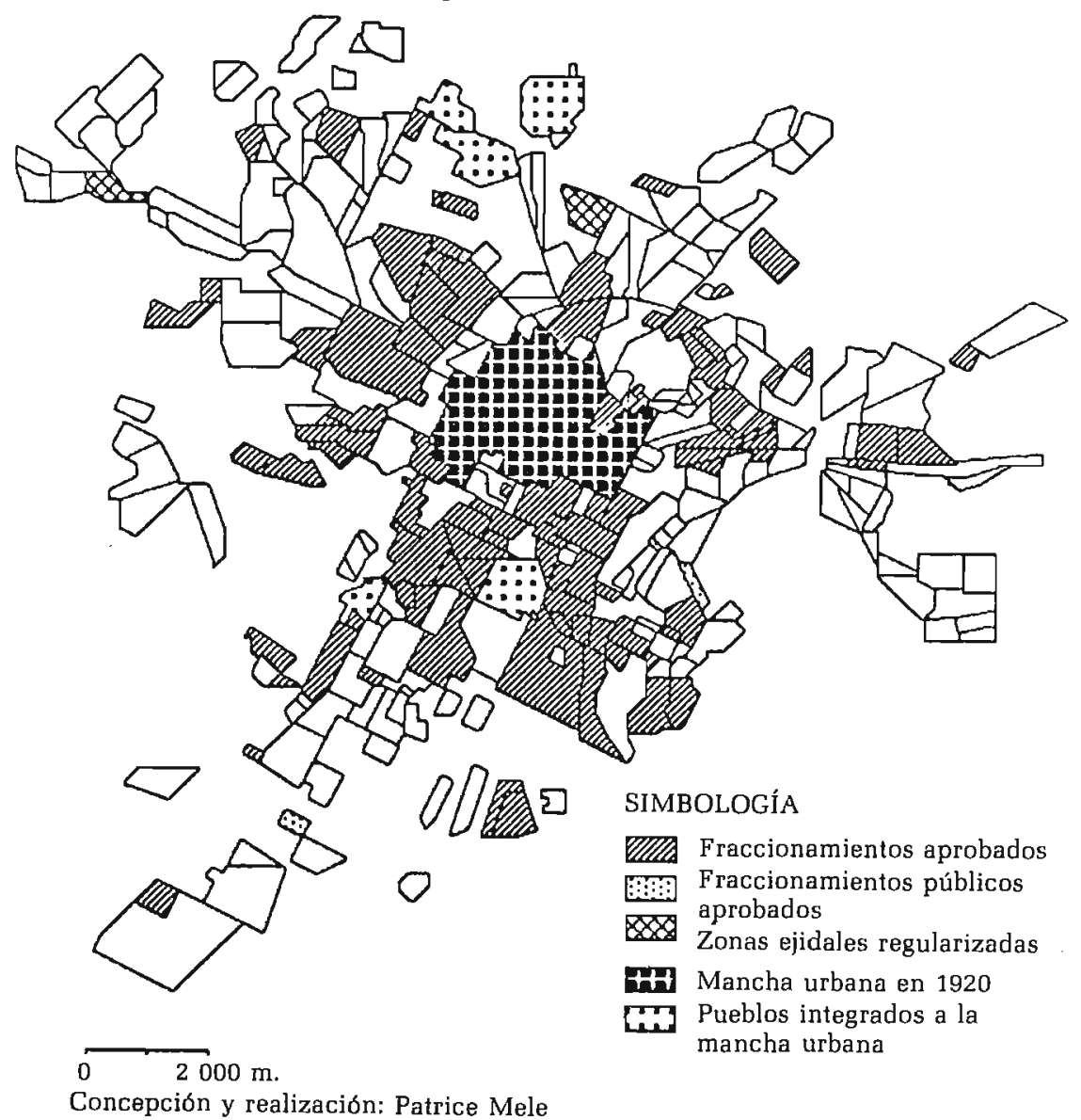

cionadores por imponerlos, a pesar de los escándalos periódicos cuando un fraccionador no cumple con sus "promesas".

En los últimos años, parece que los poderes públicos están haciendo un intento por aplicar más estrictamente la reglamentación, ya que han impuesto muchas sanciones espectaculares -paro de obras, multas, llamados al orden, prohibiciones de ventas antes de la conclusión de los trabajos de urbanización, etcétera-, pero esas sanciones sólo son puntuales y se está lejos del control real de la promoción privada. Lo que ocurre finalmente es que se 
Procesos de producción del espacio urbano de la ciudad de Puebla. Espacios de la ilegalidad

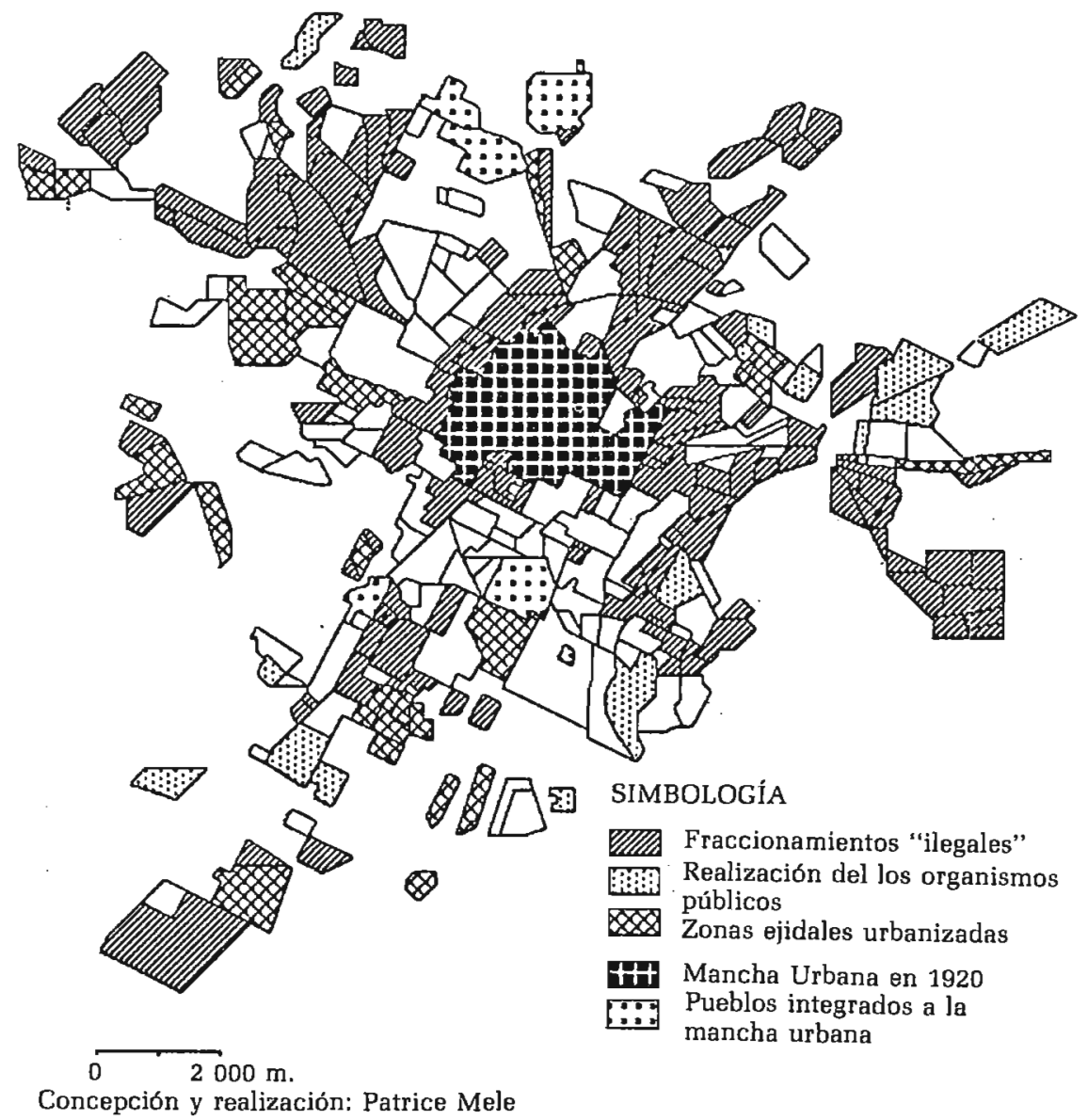

crea una situación que, conforme a los términos de la ley, no debería producirse: los habitantes de los fraccionamientos exigen a las autoridades municipales la introducción de los servicios urbanos prometidos por el fraccionador, cuando se supone que la presencia de los habitantes en los fraccionamientos debería ser la prueba de que la urbanización ya fue terminada.

Cuando las casas son construidas y habitadas antes de la terminación de las obras, las autoridades municipales pierden su medio de presión más importante: el otorgamiento o el rechazo de la 
autorización de la venta de lotes. En ese caso, la ley establece que el fraccionador debe otorgar una caución ${ }^{10}$ y que la municipalidad debe llevar a cabo la terminación de los trabajos; una vez concluidos éstos, las autoridades municipales deben obligar a los fraccionadores a pagar. En realidad, ese recurso nunca ha sido utilizado; sin embargo, es necesario hacer notar que, aunque la mayoría de los fraccionamientos se encuentra en una situación irregular o de "vaguedad" jurídica, el municipio, por lo general, aprueba y toma a su cargo rápidamente los fraccionamientos de "primera", en los que la calidad de los trabajos de urbanización es a menudo un argumento de venta.

Por lo tanto, a pesar de las apariencias, la legalidad de esa forma de urbanización es a menudo problemática. Nos recuerda una situación de "desfavorecidos" que recurren a las autoridades municipales para obtener la introducción de los servicios urbanos y buscan que se les reconozca su "derecho de ciudadanía" mediante una reivindicación de pertenencia a escala de la ciudad y no del fraccionamiento. Esa situación parece similar a la que Henri Coing denomina "la expresión de una especie de crédito que tiene un habitante contra el Estado cuando se instala en alguna parte y espera recibir la infraestructura y los servicios necesarios" [Coing, 1980]. Y la reivindicación es mucho más fuerte en este caso, puesto que los habitantes de fraccionamientos privados se consideran como elementos de una forma de producción de espacio urbanizado que, teóricamente, ofrece todas las garantías en cuanto a servicios y legalidad.

Definido téoricamente por una reglamentación estricta que busca resolver los problemas urbanos desde su aparición, el fraccionamiento privado participa, no obstante, en el aumento de los problemas urbanos de la ciudad. Puesto que no cumple con las normas fijadas por las instancias que administran el crecimiento urbano, una gran parte de los fraccionamientos privados puede ser considerada como elemento de un conjunto de la "subintegración jurldica".

Zonificación y control del crecimiento urbano

A partir del periodo del presidente Echeverría (1970-1976), los planes de equipamiento y zonificación urbana y los primeros inten-

\footnotetext{
${ }^{10}$ Según la ley de fraccionamientos, en el momento de la solicitud de autorización, debe pagarse a la municipalidad una caución de $20 \%$ del costo de las obras de urbanización.
} 
tos de equipamiento del territorio fueron dotados de una base jurfdica que los hizo potencialmente funcionales. La Ley General de Asentamientos Humanos de $1976^{11}$ permitió la publicación, en 1978, del Plan Nacional de Desarrollo Urbano y el establecimiento de un sistema nacional de planificación, elaborado esencialmente por la Secretaría de Asentamientos Humanos y Obras Públicas del gobierno federal (SAHOP), que prevé la realización de planes a los niveles estatal, municipal y local.

En la ciudad de Puebla, el Plan Director Urbano, Ciudad de Puebla, fue aprobado en $1980^{12}$ y es la continuación del Plan de Mejoramiento Urbano de la Ciudad de Puebla, de 1959, y del Plan Regulador de la Ciudad de Puebla, de 1952. Si bien es cierto que estos dos últimos planes proponían una zonificación y reservas para la urbanización, no tenían ninguna base jurídica y sólo fueron reflejo de la voluntad de los gobernantes de la época. La situación del plan director urbano es diferente, ya que la legislación nácional cuenta con un relevo local desde 1977 en la Ley de Desarrollo Urbano del Estado de Puebla, ${ }^{13}$ que precisa las condiciones de la aplicación de la zonificación y de las medidas propuestas.

El primer paso para la creación de un fraccionamiento es, en efecto, una "autorización de uso del suelo" acordada por la SAHOPEP sobre la base de la zonificación del plan director urbano. Durante los cinco últimos años, no obstante, la capacidad de las instancias administrativas de la ciudad para controlar el crecimiento urbano ha sido puesta en tela de juicio por la situación jurídica del plan director urbano.

A pesar de la existencia de los procedimientos jurídicos necesarios, el plan director, aprobado en 1980, sólo pudo adquirir un carácter de zonificación funcional en 1985, fecha en la que fue inscrito en el Registro Público de la Propiedad. Jurídicamente, los certificados de uso del suelo expedidos por la SAHOP sólo tuvieron un valor indicativo hasta esa fecha. Esa fragilidad del apoyo jurídico de un plan que se dice rector del crecimiento urbano pone en tela de juicio la situación de la planificación del crecimiento urbano.

El retardo en el registro del plan, explicado oficialmente por la lentitud inherente al sistema administrativo, se debío a un blo-

${ }^{11}$ Ley General de Asentamientos Humanos, en Diario Oficial, México, 24 de mayo de 1976 .

${ }^{12}$ Gobierno del Estado de Puebla, Gobierno del Municipio de Puebla, Plon Director Urbano, Ciudad de Puebla. Puebla, 1980, $319 \mathrm{pp}$.

${ }^{13}$ "Ley de Desarrollo Urbano del Estado de Puebla", en Periódico Oficial. ... Puebla, 1 de febrero de 1977. 
queo político. Tanto más cuanto que, según incluso la opinión de todos los funcionarios de la administración de la ciudad, el plan ya fue rebasado por la realidad del crecimiento urbano y se encuentra en proceso de revisión.

Así, el establecimiento tardío de las bases jurídicas del plan sólo es presentado como un paso necesario para la realización de un nuevo plan, el cual es presentado, a su vez, como el instrumento que no había podido ser el plan director de 1980 para la reorganización y el control del crecimiento urbano de la ciudad. Paradójicamente, podría decirse que, para conservar cierta credibilidad, en el momento en que se hace pública la acción del gobierno sobre lo urbano, el plan debe ser modificado para tomar en cuenta y hacer desaparecer las contradicciones entre la realidad del crecimiento urbano y la zonificación prevista por el texto en vigor. En consecuencia, es el plan el que debe adaptarse a la extensión de la ciudad y no el crecimiento urbano el que debe ser controlado por el plan.

En efecto, la comparación de una gráfica de los tipos de producción de espacio urbano con la zonificación del plan (Mele, 1985) revela que todos los fraccionamientos aprobados al oeste, entre el Atoyac y los límites del municipio (a lo largo de la vía rápida a Cholula y, sobre todo, de la carretera a Atlixco), se encuentran en una zona que debe ser reservada al uso agrícola. Sólo los fraccionamientos que se establecen al sur de la ciudad están de acuerdo con el plan, que define toda esa zona como el espacio de crecimiento de la ciudad.

Sin embargo, el demostrar que debe ponerse en tela de juicio la eficacia de la zonificación del plan -incluso únicamente respecto a la fórma del crecimiento urbano, que, codificado estrictamente, debería insertarse en los esquemas establecidos por las instancias locales de administración de la ciudad- no debe llevar a considerar la planificación como totalmente inoperante. Existe cierta autonomía entre la administración cotidiana del crecimiento de la ciudad y un texto que, lo hemos visto, es el relevo de una política nacional de organización del territorio basada en la ciudad.

Si bien es cierto que la administración cotidiana del crecimiento urbano es esencialmente pragmática, ya que se adapta mediante acciones precisas a las relaciones de fuerza, a las necesidades políticas y al pèso local de la especulación con bienes raíces, la ideología urbana de la planificación, por el contrario, hace del fraccionamiento una forma de producción de espacio urbano que debe inser'arse en una zonificación de la ciudad establecida sobre la base de la separación de las funciones y de los tipos de espacios urbanos. La publicidad hecha en la época de la aprobación del 
plan, tendente a demostrar la coherencia de la intervención de los poderes públicos en lo urbano y la posibilidad de una solución tecnocrática y esencialmente espacial para los problemas de la ciudad, cedió rápidamente el paso a un olvido del plan. En efecto, en comparación con el crecimiento real, el plan se reveló, por el contrario, como un instrumento de demostración de la colusión del poder local con intereses distintos a los del mejor funcionamiento de la ciudad.

No obstante, la existencia misma del plan permite a los administradores de la ciudad atribuir el problema no a la naturaleza del poder local, sino a una simple distorsión entre los objetivos y las realizaciones, distorsión cuya causa debe buscarse en las resistencias de la sociedad o del funcionamiento de la ciudad que el plan busca modificar. Consecuentemente, el plan corresponde a una imagen de la voluntad política. Incluso cuando los funcionarios públicos reconocen el fracaso del plan, lo que debe revisarse, según ellos, son los medios para ponerlo en práctica, ya que son éstos los que han sido superados por la rapidez del crecimiento urbano. Además, existe una relación particular entre los fraccionadores y el poder político ${ }^{14}$ que hizo que la voluntad de planificación se detuviera antes del establecimiento de las bases jurídicas del plan, por lo que el hecho de que éste no funcione depende de la identidad del poder local y del sistema político de administración de la ciudad.

Todo un aparato jurídico (ley de fraccionamientos) y urbanístico (planes y reglamentos) delimita lo que debería ser una urbanización "legal" y prevé todos los pasos de la integración de ésta a la ciudad; sin embargo, y no solamente por incapacidad técnica para hacer aplicar los proyectos, la ley sólo regula una parte del crecimiento urbano. En cuanto al plan, no se puede evaluar su capacidad para canalizar la urbanización, porque sólo tuvo las bases jurídicas para su aplicación después de haber sido vapuleado durante cinco años por un rápido crecimiento urbano. Por lo tanto, la definición del espacio de la "legalidad" sería:

Residual: el conjunto de los fraccionamientos aprobados y recibidos por la municipalidad, del cual se encuentra excluida la mayor parte del espacio urbano. En este caso, aunque sea otro el contexto, podemos retomar la crítica que hace Michel Foucher al

\footnotetext{
${ }^{14}$ El ejemplo más significativo es el de un exgobernador muy vinculado con los medios de la promoción inmobiliaria y fraccionador él mismo. Otros promotores importantes son miembros también de las grandes familias de industriales textiles cercanas al poder local.
} 
recurso a la noción de "ciudad de referencia" y que lo lleva a preferir el término de "hábitat de un gran número" al de barrio subintegrado; dice Foucher: "podemos preguntarnos. . si, en 1980, ]c 'ciudad de referencia' no es cada vez más ese subconjunto espacial de los barrios subintegrados" (Foucher, 1980:132).

- Teórico: circunscrito por la legislación y el corpus urbanístico existente. Éste funciona como una imagen de la buena voluntad urbana de los administradores, que retoman esquemas y concepciones heredadas de Europa o Estados Unidos. Tal parece que se pone por delante el sistema de planificación como prueba de los esfuerzos de equipamiento y de lucha contra los problemas de la ciudad. Se evoca la irreductibilidad del crecimiento urbano para justificar el fracaso del plan, cuando, verosímilmente, su aplicación no ha sido llevada a término debido a la influencia de grupos de presión locales, de promotores inmobiliarios o de industriales, y de los diversos sectores del PRI, cuyo peso condiciona la cotidianeidad de la administración urbana.

\section{B) Los espacios de la ilegalidad}

\section{Los fraccionamientos ilegales en terrenos privados}

Una parte importante del crecimiento en forma de fraccionamientos privados puede ser calificada como ilegal. Se trata de todos los fraccionamientos que no cuentan en ningún momento con una autorización oficial.

Es necesario insistir en el carácter limitado de toda clasificación, ya qúe, entre los fraccionamientos privados legales y los fraccionamientos privados ilegales, se da todo tipo de modalidades intermedias. Así, algunos fraccionamientos legales suelen violar la ley una vez aprobados, mientras que numerosos fraccionamientos ilegales siguen escrupulosamente-la reglamentación en lo que concierne a la superficie de donación y a la de los lotes, aspirando a un reconocimiento ulterior.

Para identificar los elementos que caracterizan esa forma de promoción, es preciso mostrar que no existe diferencia estructural entre los dos tipos de fraccionamiento, sino que sus actores son sensiblemente diferentes (pequeños intermediarios, "licenciados", agentes inmobiliarios informales, etcétera), como lo atestigua este ejemplo: al sur de la ciudad, en el límite de la urbanización, está escrito en grandes caracteres "últimos lotes" sobre una banderola atada entre un pequeño automóvil y un árbol cercano. Ese automóvil es la oficina de un agente inmobiliario que no sola- 
mente ofrece casas en "fraccionamientos ilegales" ya existentes, sino también los primeros lotes de un fraccionamiento ilegal en un terreno privado y la posibilidad de adquirir terrenos en una "zona ejidal" (Mele, 1986).

Por el momento, ese fraccionamiento clandestino no ofrece ningún servicio, sino que, una vez vendidos todos los lotes, el fraccionador (en este caso, el propietario, "ayudado" por el agente in. mobiliario) se compromete a introducir los servicios con el dinero de la aportación inicial ("enganche"). Los lotes son baratos y es posible adquirirlos con un crédito ventajoso.

El incumplimiento de lo establecido por la ley se hace presente en este caso como algo que permite lotificar a precios interesantes, ya que la aportación de los compradores es lo que debe permitir la realización de las obras de urbanización.

Por lo demás, el funcionamiento real de la urbanización de los fraccionamientos legales no está lejos de ese procedimiento.

En el extremo opuesto de esos espacios habitacionales para una población pobre, existe otro tipo de fraccionamiento "ilegal" correspondiente a una forma de hábitat para clases acomodadas que presenta todos los servicios. En efecto, muchos fraccionamientos de lujo han sido creados sin ninguna aprobación, en particular a lo largo de la vía rápida a Cholula. En esos fraccionamientos, el espacio interior, delimitado a menudo por un alto muro, está destinado a permanecer privado; además, los lotes son amplios, y esos espacios proponen una garantía de "seguridad", ya que un servicio de policía privada selecciona las entradas. En este caso, e] incumplimiento de la reglamentación se hace presente como algo que permite una urbanización sin control ni limitación del espacio privado.

Aunque mucho menos numerosos que los fraccionamientos ilegales para gente de bajos recursos, los fraccionamientos ilegales para personas con altos ingresos constituyen, junto con los residenciales aprobados, los lugares de residencia más prestigiosos, pero también los más segregados de la ciudad.

Las formas ilegales de producción de fraccionamientos privados no son característícas de un tipo de hábitat único, sino de un tipo particular de promoción que puede hacer abstracción de un reconocimiento:jurídico inmediato y que comprende relaciones diferentes con la ciudad. En el caso de uno de los tipos de fraccionamientos, se trata del privilegio de una población de altos recursos a la que se ofrece una relación exclusiva con la ciudad, sin ninguna necesidad de aprobación o de garantías de servicios consignadas por la ley de fraccionamientos, ya que no está considerado el que la municipahidad los tome a su cargo. En el otro caso, se trata 
de la necesidad que tiene una población de escasos recursos de adquirir un lote barato mediante una forma de promoción que no aporta ninguna seguridad. En este caso, tanto los habitantes como el "promotor" desearían que, eventualmente, la municipalidad tomara a su cargo el fraccionamiento, ya que ello aseguraría la legitimidad del asentamiento y descargaría al fraccionador de la responsabilidad del espacio interior.

Los poderes públicos no toman en cuenta esos fraccionamientos ilegales, porque en ningún momento se presentan como fraccionamientos. Las ventas son realizadas mediante procedimientos jurídicos reservados para la venta de los terrenos aislados. En el caso de los fraccionamientos ilegales cuyos lotes son grandes y que serán ocupados por poblaciones de altos recursos, el alto muro que protege de las miradas de numerosos fraccionamientos ilegales puede explicarse también como la voluntad de ocultar el inicio de las construcciones.

La intervención de los poderes públicos no es necesaria, ya que no existe conflicto con los habitantes ni demanda de parte de éstos. Si los contratos de promesa de venta o los títulos provisionales entregados por los promotores no pueden ser registrados oficialmente en ocasiones, ello no se debe a un bloqueo voluntario por parte de los poderes públicos o a una prohibición de fraccionar, sino a una falta de claridad jurídica de los derechos del vendedor.

La invasión: estrategia de construcción de una situación de ilegalidad

Si bien es cierto que, en numerosas ciudades de América Latina e incluso de México, la invasión ha sido una de las principales formas de producción de espacio urbano durante ciertos periodos (véanse Gilbert y Ward, 1985:75-92; Núñez, 1984:101; Foucher, 1980:132), en la ciudad de Puebla, las invasiones nunca fueron una forma de acceso al suelo urbano que hubiese tenido una importancia determinante en la dinámica de la urbanización.

Los asentamientos en tierras ejidales no son realmente invasiones de tierra; lo que ocurre más a menudo es que los ejidatarios vendan sus tierras, directamente o a través de "agentes inmobiliarios informales". Las tierras ejidales son objeto de una vigilancia muy estrecha por parte de sus poseedores, por lo que una invasión en tales condiciones no representaría garantía alguna de una solución rápida o de un statu quo negociado que son, lo veremos, una necesidad para los "invasores".

Sólo logramos identificar dos invasiones de tierra ejidal, las 
cuales terminaron en un desalojo por la fuerza. En rèalidad, la primera ocultaba un conflicto de tierras entre dos ejídos, pero, ante la expulsión, lo que se invocó fue la necesidad de terrenos para construir, no ese conflicto agrario irresuelto desde hacía muchos años. ${ }^{15}$

Más generalmente, las invasiones de tierras se llevan a cabo en terrenos privados o públicos. De las siete invasiones importantes que pudimos identificar en Puebla, dos terminaron en la expulsión de los invasores, tres en el reacomodo de los "colonos" conforme a programas de vivienda públicos y dos en la regularización de los terrenos en disputa. Las invasiones no aparecen en los mapas que presentamos porque, a diferencia de los fraccionamientos ilegales, su statu quo nunca es respetado.

En la mayoría de las invasiones, pudimos identificar como uno de sus factores la voluntad de establecer una relación de fuerza y una negociación con las instancias administrativas, por lo que, en general, se localizan en terrenos públicos o en un lugar que permite implicar directamente al Estado o a la municipalidad.

En este caso, la relación entre invasión y necesidad de tierra no consiste ya en apropiarse de un terreno para instalarse en él, sino en tomar posesión de un terreno público, o algún otro para el que existe un proyecto de equipamiento, creando así una situación de ilegalidad que exige la intervención del Estado y, por ende, una negociación y un eventual reacomodo. Lo más importante en este caso es hacer público el hecho, lo cual hace imposible el arreglo por la fuerza. En la elección de un terreno, los "invasores" toman en cuenta, por supuesto, la ubicación del mismo, pero también la importancia que puede tener para la opinión pública la política urbana del Estado destinada al tipo de terreno en cuestión.

Consecuentemente, la invasión es un medio para crear una situación de ilegalidad con la que se busca que los poderes públicos tomen a su cargo la necesidad de vivienda de personas que, así, se definen como un grupo que requiere una atención prioritaria. Y los representantes del gobierno del estado o del municipio intervienen siempre en ese sentido, buscando acallar toda situación de ilegalidad pública, toda manifestación pública de la autonomía del crecimiento urbano, del irrespeto de las normas jurídicas; pero también se trata de tomar en cuenta, mediante soluciones negociadas, el problema de vivienda de personas a las que el acto de la violación de la propiedad de la tierra presenta como potencialmente peligrosas, incontrolables y, por lo tanto, como personas

${ }^{15}$ Cf. El Sol de Puebla, 12 de febrero de 1982. 
que ponen en tela de juicio, o aparentan hacerlo, la administración urbana del poder local.

Los asentamientos ilegales en tierras ejidales

El 42\% de la superficie del municipio de Puebla está compuesto por tierras ejidales. Las primeras resoluciones presidenciales de dotación de tierras datan de 1921, pero la mayoría de las tierras ejidales fueron entregadas entre 1930 y 1935 y los últimos terrenos afectados fueron distribuidos en 1977. Debemos hacer notar la continuidad de los procesos de la reforma agraria y la importancia que toma la propiedad ejidal de las tierras en torno a la ciudad de Puebla. Los ejidos constituyen, por ende, un espacio privilegiado de la difusión del crecimiento de la ciudad; los asentamientos ilegales en tierras ejidales se hacen en la contigüidad del espacio urbano, a lo largo de los ejes, pero también a cierta distancia de la urbanización existente, en particular al sur y al suroeste.

Los asentamientos ilegales en zonas ejidales no son asimilables a las "invasiones"; corresponden, generalmente, a ventas de tierra hechas por los propios ejidatarios. Esas ventas pueden tomar la forma de fraccionamientos ilegales, aunque también pueden ser la extensión de un procedimiento puesto en práctica por la reforma agraria: las zonas urbanas ejidales reservadas para la construcción de casas para los ejidatarios, pero que también son vendidas a habitantes de la localidad que no son ejidatarios (cf. Durand, 1983:71; Mele, 1986:330-351; Varley, 1985).

Jorge Durand (1983) mostró que, en el Distrito Federal, la presión de la urbanización sobre las tierras ejidales se manifiesta mediante compradores que buscan directamente a los ejidatarios para tratar de adquirir de ellos un trozo de tierra. En Puebla, esa forma de relación con la ciudad corresponde a los primeros asentamientos en tierras ejidales en los años 1950, cuando había cierta simbiosis entre la población ejidal mayoritaria y los nuevos habitantes. Ese tipo de presión sigue existiendo actualmente, si bien ahora se ha generalizado debido a la necesidad de tierra para la autoconstrucción, además de que se ha creado un mercado de tierras ejidales.

En la ciudad, la promoción se hace, ya en forma oral, ya mediante carteles que, colocados en los pequeños comercios de los barrios populares, ofrecen terrenos en venta. Los lotes están delimitados con precisión y son menos caros y a menudo más grandes (de 300 a $500 \mathrm{~m}^{2}$ ) que en los fraccionamientos privados apro- 
bados o incluso que en los fraccionamientos "ilegales" en tierras privadas.

Con todo, si bien es cierto que el fraccionamiento popular es el más común, en él surgen contradicciones con la imagen de urbanización clandestina atribuida al adjetivo "ilegal" que ponen en tela de juicio la existencia de un vínculo unívoco entre la tenencia preexistente de la tierra y el espacio urbano producido.

En las tierras ejidales es posible descubrir la introducción de servicios municipales o federales (postes de Teléfonos de México, estación de bớmberos de la municipalidad, etcétera). La integración de esos servicios públicos a la urbanización en zonas ejidales tiene lugar como parte de un plan de negociaciones informales. Los ejidatarios - "ayudados" siempre por un "asesor" "licenciado" o "ingeniero" vinculado a menudo con los poderes públicos)- ofrecen tierras a los organismos públicos y, consecuentemente, cuentan con la garantía de que la regularización se hará rápidamente y de que podrán contínuar fraccionando sin problemas.

Otra particularidad consiste en que, en Puebla, es imposible asimilar los asentamientos en tierras ejidales a las zonas de vivienda precaria para personas de ingresos modestos, ya que existen zonas residenciales establecidas en tierras ejidales. Los primeros asentamientos tienen más de treinta años de antigüedad y, en ciertos casos, se produjo un proceso de modificación de la composición socioprofesional. Aunque los primeros compradores formaban parte de una población de bajos ingresos, más tarde (en partícular en torno a La Paz, barrio residencial de lujo), algunas personas compraron tres o cuatro lotes para construir conjuntos habitacionales de calidad y se unieron para introducir todos los servicios, creando, consecuentemente, una modifícación de.la imagen urbana sin que la situación de la tierra hubiese cambiado. En este caso, por lo tanto, el statu quo ofreció un carácter de estabilidad suficiente para que se produjera esa evolución.

La respuesta que dan los poderes públicos a los problemas de los asentamientos ilegales es la regularización, es decir, el reconocer una situación de hecho mediante el otorgamiento de títulos de propiedad a las personas que viven en las tierras ejidales. Es significativo que el vocablo utilizado para designar esas ocupaciones sea "asentamiento", es decir, establecimiento. Sólo hacemos constar el fenómeno: gente que habita en tierras ejidales. No es la génesis de esos asentamientos lo que se pone en tela de juicio; y. ello es así porque, si fuesen definidos como invasión o como venta ilegal, se harían acreedores a una sanción.

Un organismo creado en 1974, la Comisión de Regularización de la Tenencia de la Tierra (Corett), se encarga de arreglar el pro- 
blema. La tarea de Corett consiste en detectar las zonas de asentamientos ilegales y en promover su regularización mediante la expropiación de utilidad pública, la indemnización de los ejidatarios y la venta a los poseedores actuales. Cuando se detecta un asentamiento (en principio, quienes solicitan la regularización son los compradores), se hace un levantamiento del terreno. Las relaciones con los ejidatarios son difíciles a menudo, ya que, si no han terminado de vender toda su tierra, se oponen a la regularización, señalando a los compradores como invasores y acusando a la Corett de querer robarles su tierra. Para arreglar ese problema, se utiliza un proceso de control social, no administrativo, sino político. Para hacer entrar en razón a los ejidatarios, Corett actúa entre los dirigentes [líderes de los movimientos o comisarios ejidales] a través de uno u otro de los medios del sistema de control político mexicano -el municipio, el estado, el PRI, las asociaciones, los sindicatos, etcétera- puesto que lo más común es que los dirigentes sean miembros de un organismo de representación vinculado más o menos directamente al PRI o que aspiren a convertirse en representantes oficiales y tengan necesidad del apoyo del sistema para conservar su posición de dominio (cf. la descripción de las relaciones entre el poder político y los dirigentes, que Cornelius llama "caciques urbanos"; Cornelius, 1980; Montaño, 1981].

En Puebla, Corett es propietaria de dos antiguas zonas ejidales que en la actualidad está revendiendo a los habitantes (en total, 1120 lotes). El resto de los asentamientos ilegales detectados e inscritos en el programa de regularización representa 18363 lotes en 11 de los 26 ejidos que rodean la ciudad, mientras que, en 1983 , el presidente municipal de la ciudad estimaba en 40000 el número de lotes creados ilegalmente. ${ }^{16}$

La acción de Corett es muy lenta, dado que, en diez años de funcionamiento en la ciudad de Puebla, sólo dos zonas han sido regularizadas; los ejidatarios y los habitantes de los terrenos recurren constantemente a las autoridades municipales o al gobierno del estado para protestar contra las demoras en la regularización. ${ }^{17}$

Quizá en esa lentitud sólo deberíamos ver el corolario de la dificultad inherente a la delimitación preliminar de los verdaderos ocupantes de las tierras, pero creemos que la lentitud se debe también a toda modificación de la propiedad de la tierra, que tiene que recorrer un largo camino administrativo en el seno de los ser-

${ }^{16}$ Cf. El Sol de Puebla, 12 de octubre de 1983.

${ }^{17}$ Véanse, en los periódicos locales en particular, las numerosas protestas del Comité de Propietarios de Lotes Ejidales Indocumentados. 
vicios de la Secretaría de la Reforma Agraria (SRA) ${ }^{18}$ y depende de una resolución presidencial. Además, Corett es un organismo que cuenta con pocos medios, no recibe créditos federales y debe autofinanciar sus acciones mediante los beneficios obtenidos entre la expropiación y la reventa de los lotes.

Esa autonomía financiera ha sido analizada por los representantes de ciertos partidos de oposición como la causa de la ineficacia de Corett, pues, según ellos, permite la corrupción y la creación de fondos importantes cuyo destino se desconoce. Sin querer pronunciarnos sobre la realidad o la amplitud de la corrupción en los procesos de regularización, podemos decir que es probable que esa autonomía financiera permita también a Corett una intervención que no se limita únicamente a los procedimientos administrativos y le da cierto margen de maniobra durante las negociaciones (también financieras) previas a su intervención en zonas ejidales conflictivas.

Aun cuando todos los asentamientos ilegales deben ser regularizados, el procedimiento administrativo sigue siendo considerado como un favor excepcional acordado por los poderes públicos ante una situación anormal. Podríamos analizar la acción de Corett como, a la vez, una banalización de la situación de ilegalidad y una estigmatización de la misma. Banalización, porque no existe sanción; estigmatización, porque, después de una verificación, Corett determina quién es el derechohabiente legítimo, el cual debe comprar un título de propiedad. Ese entorpecimiento constante de la situación jurídica de la tierra, situación cuyo estado es precario hasta la fase final de la regularización, mantiene una relación de dependencia entre las poblaciones interesadas y las instancias del poder local y nacional -bajo la modalidad del juramento de fidelidad necesario para las instituciones políticas hegemónicas- que se traduce en un fortalecimiento del sistema de control social del PRI sobre las formas ilegales del crecimiento urbano.

Consecuentemente, la regularización consiste, conforme a este análisis, en la creación no sancionada de una situación de ilegalidad. Y es en esa situación de ilegalidad, quizá, donde se sitúa la función social de la regularización, más que en un impulso necesario para la consolidación del hábitat (según la tesis de Turner) o en una "dinamización esencial del mercado capitalista del suelo

${ }^{18}$ El representante de Corett en Puebla declaró en 1983 haber solicitado la expropiación previa a la regularización de nueve zonas ejidales de la ciudad y acusó a la SRA de no haber resuelto esos casos en tres años de gestiones. Cf. El Sol de Puebla, 26 de noviembre de 1983. 
urbano" (según las críticas de Castells, 1985:138). En efecto, la introducción de los servicios desempeña una función más importante para la consolidación de los barrios y del hábitat (Varley, 1986), consolidación que, por lo demás, a menudo es relativamente independiente de la situación jurídica de la tierra (Mele, 1986). Además, la causa principal de consolidación de los barrios por cambio de tipo de habitat es la integración al mercado de los terrenos para construcción; a partir de su creación, los asentamientos ilegales en zonas ejidales se integran a ese mercado, lo cual explica el que no exista una correspondencia directa entre el tipo de hábitat y la situación jurídica de la tierra.

$\mathrm{Si}$ bien es cierto que la regularización tiene un objetivo político bien definido, éste no consiste en el fortalecimiento de la legitimidad del régimen mediante la formación de una nueva clientela electoral a través del otorgamiento de títulos de propiedad (Núñez 1984:112) ni en la desmovilización de los habitantes de los barrios afectados (Varley, 1985:303), sino más bien en una "removilización" de los habitantes a través de canales creados por el poder. En este sentido, la eficacia de la regularización, tal como se lleva a cabo en México, depende de la prolongación del momento de la negociación, que coloca a los habitantes en una situación de demanda, de vulnerabilidad ante los organismos administrativos de la ciudad y ante el sistema de control social del PRI, ya que, en función de la cantidad, el número de lotes dístribuidos no es realmente significativo en comparación con el número de comunidades que se encuentran negociando con Corett. A menos que el análisis se valide en función de la corrupción o que se considere que los retardos son explicables por oposiciones existentes en el seno del sistema administrativo, la impotencia objetiva de Corett es precisamente la base de su eficacia social. Mientras se mantenga la situación de ilegalidad, que Corett contribuye a crear, perdurarán la negociación y, por ende, la posibilidad del control social. La regularización no es nunca simple gestión administrativa; depende de la buena voluntad del poder y de las relaciones privilegiadas que los habitantes interesados puedan crear con las instancias administrativas.

En ese contexto, los "poseedores" de lotes en tierras ejidales buscan multiplicar las relaciones con las instancias de administración de la ciudad, puesto que cada recurso, cada gestión, da un poco más de consistencia a sus derechos sobre la tierra que ocupan. Acuden espontáneamente a la Secretaría de Hacienda del Estado de Puebla para pagar el impuesto predial, esto es, el impuesto local sobre la propiedad de la tierra. La política del estado de Puebla consiste en aceptar el pago dè impuesto sobre la base 
de una carta de posesión expedida por las autoridades ejidales. Cońsecuentemente, surge otro nivel de legitimidad, anterior a la intervención de Corett, que viene a decidir sobre la realidad de la posesión de los terrenos y a acordar a las autoridades ejidales -es decir, a los comisarios ejidales, cuya función como agentes inmobiliarios informales se ve reforzada aún más-el poder de repartir oficiosamente las tierras ejidales. Los recibos de pago del impuesto predial son utilizados en todas las relaciones con los poderes públicos como certificados de posesión.

Aunque el crecimiento urbano en la forma de asentamientos en tierras ejidales es definido como clandestino, como ilegal, con base en los textos de la reforma agraria, encuentra legitimaciones ulteriores de otras instancias de administración de la ciudad, sin que la precariedad de la propiedad de la tierra sea suprimida realmente mediante las acciones generalizadas de regularización.

La no -integración jurídica de los "fraccionamientos" públicos

La acción de los organismos de ayuda a la vivienda de carácter social toma a su cargo una población que -excluida de los préstamos bancarios para la compra o construcción de vivienda, para los que se exige un ingreso superior a 2.5 veces el salario mínimo- puede justificar recursos estables superiores al salario mínimo. Pero una gran parte de la población de la ciudad no tiene ninguna esperanza de acceso a ese tipo de vivienda, por lo que las formas "ilegales" y la autoconstrucción se presentan entonces como las únicas formas de producción de espacio urbano mediante las cuales esas personas pueden tener acceso a la propiedad de la vivienda: por una parte, la promoción acuerda créditos a largo plazo para la compra de terrenos sin que sea necesaria nínguna justificación de solvencia; por la otra, la autoconstrucción permite dosificar la inversión familiar y adaptar la vivienda a los recursos disponibles.

La relación entre las acciones de los organismos públicos de vivienda y el sistema jurídico que administra el crecimiento urbano puede parecer contradictoria. Una lista de fraccionamientos o conjuntos habitacionales que no habían sido aprobados y que, por ende, eran definidos como clandestinos por SAHOPEP y las autoridades municipales, pone de manifiesto la mayoría de las acciones de vivienda de los organismos públicos. Se trata, por lo demás, de los únicos tipos de fraccionamientos "ilegales" registrados por el municipio, pues los otros no están catalogados.

En efecto, si consideramos a SAHOPEP y a las autoridades mu- 
nicipales como las instancias de legitimación del crecimiento urbano, los conjuntos habitacionales del Infonavit, el Fovissste y el Indeco ${ }^{19}$ no están integrados al espacio del crecimiento "legal". Todos han sido construidos por esos organismos sin preocuparse por la reglamentación local (ley de fraccionamientos, plan), orgullosos del aval del poder federal. Más de diez años después de la creación de los primeros conjuntos habitacionales del Infonavit, los expedientes de aprobación apenas están constituyéndose, ya que son necesarios para que la municipalidad tome a su cargo los conjuntos.

Esa situación que pone en tela de juicio la legalidad de las construcciones de los organismos públicos podría ser definida como la inclusión de la mayoría de las formas de crecimiento urbano controlado por el sector público en el conjunto de la subintegración jurídica. Si adoptáramos como definición de la subintegración jurídica la falta de cumplimiento de las normas y los textos que reglamentan a escala local la extensión de la ciudad, tendríamos que considerar la mayor parte del crecimiento urbano de la ciudad de Puebla como subintegrada. Pero los habitantes de los conjuntos habitacionales del Infonavit o de los fraccionamientos del Indeco no tienen problemas de legalidad respecto a su título de propiedad, aun cuando los espacios donde viven podrían ser definidos como fraccionamientos ilegales.

Para establecer una tipología funciona] del crecimiento urbano, sería necesario volver a una definición de la ilegalidad a partir de la casa, de la unidad familiar, y utilizar la posesión individual del suelo como criterio de integración a la ciudad. Además, en lo que se refiere a los servicios, esos conjuntos no pueden ser considerados como "subintegrados". Por lo tanto, según nuestro análisis, existen barrios no integrados jurídicamente que no forman parte del conjunto de la subintegración, ya que reciben el aval de instancias de legitimación del crecimiento que pueden hacer caso omiso de la legislación local.

C) La gestión política del espacio urbano y la legitimación del crecimiento urbano

La ilegalidad tiene lugar, en consecuencia, en el seno mismo de

\footnotetext{
${ }^{19}$ Infonavit: Instituto del Fondo Nacional de la Vivienda de los Trabajadores; Fovissste: Fondo de Vivienda del Instituto de Seguridad y Servicios Sociales de los Trabajadores del Estado; Indeco: Instituto Nacional para el Desarrollo de la Comunidad Rural y Vivienda Popular.
} 
las operaciones de los organismos públicos de vivienda. Además, existe una oposición entre los organismos públicos y las instancias de administración del crecimiento urbano que hace surgir un gran número de instancias de legitimación del mismo.

El mínimo de legalidad que debe obtenerse, si bien numerosos asentamientos han hecho caso omiso de ella, es una autorización de uso del suelo en la que la SAHOPEP decide sobre la constructibilidad del terreno elegido. A este respecto, es necesario señalar la existencia de muchos conflictos, que ilustraremos con un ejemplo: un sindicato quería realizar una unidad de $36000 \mathrm{~m}^{2}$ al norte de la ciudad por cuenta del Infonavit; ${ }^{20}$ el antagonismo residía en el hecho de que los terrenos elegidos habian sido clasificados por el plan director urbano de Puebla como reservados para la industria ligera. Ante la oposición de la SAHOPEP a la ubicación elegida para la unidad habitacional, el sindicato respondió en una carta indignada: "Los programas previstos para esta zona de Puebla no pueden pasar por sobre los intereses de los propietarios de los terrenos ni los nuestros; el uso de esos terrenos no puede ni debe ser otro que la construcción de viviendas de interés social." ${ }^{21}$ En esa carta, el sindicato no cita al Infonavit y se apropia del programa, que él llama "nuestra unidad habitacional".

Como vemos, se trata de apelar a un interés público legítimo, encarnado en este caso por el sindicato, ante las decisiones de las instancias responsables del equipamiento de la ciudad. La elección que hace el Infonavit de la ubicación sólo obedece a la capacidad de los sindicatos para adquirir terrenos baratos cuya urbanización responda a sus intereses, aun cuando después sea necesario transformarlos, mediante un conflicto abierto, en terrenos adecuados para la construcción.

Ahora bien, aunque ese programa no esté incluido actualmente en los proyectos del Infonavit, ya que, según parece, prevaleció la posición del gobierno del estado, otros ejemplos muestran que, en la oposición entre esas dos legitimidades, el arbitraje del gobierno no siempre concuerda con el discurso sobre la gestión urbana.

Trátese de la realización de un conjunto habitacional del Infonavit próximo a pequeñas industrias bajo la presión de un sindicato, o de un fraccionamiento promovido por una asociación miembro de la Confederación Nacional de Organizaciones Populares (CNOP; el sector popular del PRI) que recibe la aprobación del go-

${ }^{20}$ Es necesario recordar que el promotor (sindicato o asociación) elige el lugar y los planos y construye; el Infonavit desempeña la función de proveedor de fondos.

${ }^{21} \mathrm{Cf}$. la carta del sindicato a la SAHOPEP en el Expediente Las Fuentes, Infonavit, archivo de la SAHOPEP. 
bierno del estado dos días antes de que éste haya aprobado el plan director en el que se clasifica el terreno como zona de preservación ecológica, podemos establecer la existencia de un "interés público" que se opone a la acción de los responsables del equipamiento urbano. Frente a una lógica de acción sobre lo urbano que busca establecer una zonifícación para transformar Puebla en una ciudad "funcional", es decir, sin conflictos, parece ser que los gobiernos federal o estatal dan prioridad al sector obrero (sindicatos promotores del Infonavit) o al sector popular del PRI (asociaciones miembro de la CNOP).

Aunque no excluimos la posibilidad de un análisis desde el punto de vista de la especulación y de los intereses particulares de los dirigentes de los sindicatos o de las diversas organizaciones miembros del PRI, vemos también que predomina la voluntad de promover otro tipo de solución para los conflictos.

Opuesta a los instrumentos tecnocráticos que se han propuesto para hacer frente a las contradicciones urbanas, existe una lógica populista de integración de las reivindicaciones sociales. La legitimidad de la acción de planificación espacial del estado es puesta en tela de juicio por una legitimidad más importante, sobre la cual reposan las instancias de integración del apoyo popular del régimen.

Por otra parte, si pensamos en el particular funcionamiento del Infonavit, es plausible considerar que, en las oposiciones y la selección de asentamientos, es mayor el peso local de los sindicatos que el de un organismo federal descentralizado. Debido a ello, las contradicciones no pueden ser consideradas como una oposición entre el poder central y el poder local.

Además, ciertos elementos del poder local, al igual que ciertos sectores del poder central, actúan conforme a una lógica administrativa alejada de la negociación populista. También es necesario recordar el estricto control que ejerce el poder central sobre las autoridades locales que administran la ciudad. Consecuęntemente, parece ser que se trata más de una oposición entre "sectores" que forman parte del "sistema" de poder mexicano que entre dos escalas de poder.

El modo de organización específico de los poderes locales, que reflejan a la escala de la ciudad las relaciones de fuerza nacionales organizadas en torno al PRI, ha permitido la multiplicación de las instancias de legitimación del crecimiento urbano. Por otra parte, la imbricación entre las instancias políticas locales y los medios interesados en la promoción y la especulación urbana hace posible la existencia de una brecha importante entre las normas y la realidad del crecimiento urbano. 


\section{Conclusión}

La "ilegalidad" de cierto número de formas de producción de espacio urbano no se traduce en la existencia de una precariedad, de una inseguridad, que sería síntoma de una falta de integración, de una subintegración, sino, más bien, en una integración que toma el rodeo de la necesidad de una legitimación, de un reconocimiento de la inclusión en la ciudad. El control político y social que las asociaciones, sindicatos u organismos dependientes del PRI ejercen sobre los habitantes de los espacios periféricos de la ciudad se ve reforzado por el mantenimiento de promesas de fidelidad basadas en la esperanza de la regularización de la propiedad de la tierra o de la introducción de servicios.

No se trata de recurrir a una estrategia política explícita, sino de mostrar cómo cada forma de promoción inmobiliaria se define por su relación con el poder. La especificidad de ese modo de organización del poder político es lo que otorga su originalidad a cada forma de crecimiento de la ciudad y lo que valida un análisis desde el punto de vista de las formas de producción del espacio urbano. Conforme a esto, la forma de producción que debería estudiarse tomando en consideración el modo de definición o de negociación frente a las instancias institucionales o informales de poder del PRI.

La multiplicidad de instancias de legitimación y de reconocimientos oficiales u oficiosos desempeña una función integradora de las diferentes formas de producción del espacio urbano que, así, evita la confrontación directa entre la norma jurídica y la realidad de la urbanización y, también, entre las instancias administrativas de la ciudad y la población de los espacios periféricos. Las contradicciones entre la voluntad de gestión y la realidad del crecimiento no pueden analizarse exclusivamente en función de la impotencia de los poderes públicos, ya que revelan también la preeminencia de un modo de control social "populista".

La dinámica de la urbanización de los espacios periféricos no puede analizarse en función de la exclusión de una población "marginada" de las formas de crecimiento legítimo de la ciudad; sin embargo, una parte de la población no tiene acceso al mercado de la promoción privada "legal" y no es tomada en cuenta por la promoción pública.

En Puebla existen dos mercados de la promoción inmobiliaria, interesados en los mismos tipos de espacios, que podrían diferenciarse por el grado de inversión necesario para la promoción. Los fraccionamientos "legales" requieren un capital de promoción importante, mientras que una acción de promoción "ilegal" 
sólo necesita la posesión del terreno y que la urbanización en tierras ejidales se haga a partir de la alianza entre las autoridades ejidales y un consejero técnico que tome a su cargo la delimitación de los lotes y la relación con el poder local.

Con todo, los lazos entre los que participan en cada uno de esos mercados y el hecho de que las poblaciones de altos ingresos o solventes puedan recurrir indiferentemente a cualquiera de los dos mercados no permiten asimilar éstos a los dos circuitos de la economía urbana identificados por Milton Santos (1975) ni validar la división fundamental que se hace en los análisis resumidos en la primera parte entre una urbanización "legal" y una urbanización "ilegal".

Así, parece más interesante definir la dinámica de la urbanización de la ciudad de Puebla como la expresión de los diferentes actores que intervienen en el mercado de la promoción inmobiliaria que oponer el mercado "legal" al "ilegal". Consecuentemente, podemos concluir que la multiplicidad de las formas de integración jurídica y de los reconocimientos "oficiales" u "oficiosos" sancionan las diversas formas del crecimiento y no la existencia de "sistemas jurídicos informales" (Pérez Perdomo y Nikken, citado por Azuela, 1984:106) propios de las formas "ilegales" de producción de espacio urbano.

En cuanto a la "ilegalidad", ésta sólo puede permanecer como centro del análisis de la ciudad si intentamos efectuar un estudio de las condiciones en que surge la creación social de situaciones de ilegalidad.

Cuando la ilegalidad es una designación utilizada por las instancias del poder local, en oposición a una ciudad legal cuya inconsistencia hemos visto, su única eficacia consiste en que vuelve a colocar a las autoridades municipales y a las instancias del poder político en el centro de la definición del "derecho a la ciudad" y de la identidad de ésta.

El hecho de hacer pública la exclusión no debe considerarse como un instrumento de legitimación de la'otra parte de la ciudad, sino como una construcción social que coloca al poder político local'en una posición de intermediario entre la ciudad "legal" y las poblaciones que habitan espacios urbanos producidos en forma ilegal. La multiplicación de las instancias de legitimación y de los reconocimientos oficiosos constituye, por ende, la concesión de un "derecho de ciudadanía" informal que condiciona la integración a la ciudad y permite un acceso negociado a las instancias de administración del espacio urbano.

Cuando una situación de "ilegalidad" es creada por los invasores de terrenos públicos, el fin es el mismo. Al reivindicar la ex- 
clusión, reivindican la atención de los poderes públicos y ese acceso negociado a las instancias de gestión del espacio.

Si la negociación es necesaria en una situación de "ilegalidad", ello es así porque la ilegalidad hace plausible el uso legítimo de la sanción, de la fuerza, del desalojo, y, por el contrario, una situación de ilegalidad hecha pública exige la atención de las autoridades. En este sentido, la creación de situaciones de "ilegalidad" constituye un acto de poder que fundamenta su legitimidad.

\section{Bibliografía}

Azuela, A., 1974, "Hacia una sociología de la urbanización popular", en Revista A, vol. V, núm. 11. México, UAM-Azcapotzalco, 1974, pp. 93-112.

Bennholdt-Thomsen, V., 1981, "Marginalidad en América Latina: una crítica de la teoría", en Revista Mexicana de Sociología, año XLIII, núm. 4. México, IIS-UNAM, 1981, pp. 1505-1545.

Castells, M., 1985, Crisis urbana y cambio social. México, Siglo XXI, $1985,322 \mathrm{pp}$.

Coing, H., 1980, La Croissance périphérique des villes du Tiers Monde et le röle de la promotion foncière et immobilière (Mesa Redonda del Coloquio Travaux et Documents de Géographie Tropicale, núm. 40, CEGET, CNRS, 5-7 de mayo de 1977). Bordeaux Talence, $1980,543 \mathrm{pp}$.

Durand Lasserve, A., 1985, L'Exclusion des pauvres dans les villes du Tiers Monde, París, l'Harmattan, $197 \mathrm{pp}$. y J. F. Tribillon, 1983, "La production foncière et immobilière dans les villes des pays en développement", en Hérodote, núm. 31. París, Maspéro, 1983, pp. 9-43.

Foucher, M., 1980, 'L'Hlabitat du grand nombre dans les villes d'Amérique Latine", en Hérodote, núm. 19. París, Maspéro, 1980, pp. 123-154.

George, P., 1967, "L'Habitat spontané, parasite de l'urbanisation en pays sous-développés", en Cahiers Internationaux de Sociologie, vol. XLVII. París, 1967, pp. 13-26.

Gilbert, A., y P. Ward, 1985, Housing, the State and the Poor. Policy and Practice in Three Latin American Cities. Cambridge, Cambridge University Press, 1985, $319 \mathrm{pp}$.

Lacoste, Y., 1976, "Géographie du sous-développement". París, PUF, 1976, $292 \mathrm{pp}$.

Mele, P., 1986, La Dynamique de l'urbanisation de la ville de Puebla, de la ville à la région urbaine (tesis de doctorado de tercer ciclo, Université de Paris III), 1986, $471 \mathrm{pp}$.

et al., 1985, Cartografía temática de la ciudad de Puebla, División de Estudios Geográficos, Mapoteca Dr. Jorge A. Vivó. Puebla, ICUAP, 1985, 10 mapas, $1 / 40000$.

Naciri, M., 1980, "Les Formes d'habitat 'sous-intégrées' ", en Hérodote, núm 19, París, Maspéro, 1980, pp. 123-154. 
Nuñez, O., 1984, "Périphérie urbaine et intervention étatique à Mexico", en Le Logement, l'état et les pauvres dans les villes du Tiers Monde. Pratiques urbaines 2. CECET, CNRS, 1984, 184 pp., pp. 99-113.

Oliven, G., 1981, "Aspectos económicos, políticos y culturales de la marginalidad urbana en América Latina", en Revista Mexicana de Sociología, año XLIII, vol. XLIII, núm. 4. México, IIS-UNAM, 1981, pp. 1627-1643.

Pradilla Cobos, E., 1984, Contribución a la crítica de la "teoría urbana". México. UAM-Xochimilco, 1984, $731 \mathrm{pp}$.

Quijano, A., 1971, "La Formation d'un univers marginal dans les villes d'Amérique Latine", en Espaces et Société, núm. 3. París, 1971, pp. 71-81.

Santos, M., 1975, L'Espace partagé: les deux circuits de l'économie urbaine des pays sous-développés. París, ditions M. TH. Genin, 1975, 399 pp.

Turner, J. F. C., 1975, "Asentamientos urbanos no regulados", en Desarrollo urbano y regional en América Latina, problemas y políticas. México, FCE, 1975, 732 pp., pp. 473-566.

Varley, A., 1985, "La zona urbana ejidal y la urbanización de la ciudad de México", en Revista A, vol. VI, núm. 15, especial: De la Metrópoli Mexicana. México, UAM-Azcapotzalco, 1985, pp. 71-93.

,1985, Ya somos dueños: Ejido, Land Development, and Regularization in Mexico City (tesis de doctorado). Londres, University of London, $1985,428 \mathrm{pp}$.

Zuñiga, V., 1985, "L'Exode rural continue dans la ville à Monterrey, Mexique", en Revue Française de Sociologie, vol. 26, núm. 3. París, julioseptiembre de 1985, pp. 455-473. 